\title{
Wideband Lithium Niobate FBAR Filters
}

\section{Thomas Baron, ${ }^{1}$ Eric Lebrasseur, ${ }^{1}$ Florent Bassignot, ${ }^{1}$ Haixia Wang, ${ }^{1}$ Sylvain Ballandras, ${ }^{1}$ Ji Fan, ${ }^{2}$ Lise Catherinot, ${ }^{2}$ Matthieu Chatras, ${ }^{2}$ Philippe Monfraix, ${ }^{3}$ and Laetitia Estagerie ${ }^{4}$}

\author{
${ }^{1}$ FEM TO-ST UMR 6174 CNRS-UFC-ENSMM-UTBM, ENSMM, 26 Chemin de l'Epitaphe, 25030 Besançon Cedex, France \\ ${ }^{2}$ Xlim, UMR 6172 CNRS, Université de Limoges, 87060 Limoges, France \\ ${ }^{3}$ Thales Alenia Space, CCEL/LPH/EA, Toulouse, France \\ ${ }^{4}$ CNES, 18 Avenu Edouard Belin, 31401 Toulouse Cedex 9, France
}

Correspondence should be addressed to Thomas Baron; thomas.baron@femto-st.fr

Received 5 October 2012; Accepted 17 December 2012

Academic Editor: Priyanka Mondal

Copyright (C) 2013 Thomas Baron et al. This is an open access article distributed under the Creative Commons Attribution License, which permits unrestricted use, distribution, and reproduction in any medium, provided the original work is properly cited.

\begin{abstract}
Filters based on film bulk acoustic resonators (FBARs) are widely used for mobile phone applications, but they can also address wideband aerospace requirements. These devices need high electromechanical coupling coefficients to achieve large band pass filters. The piezoelectric material $\mathrm{LiNbO}_{3}$ complies with such specifications and is compatible with standard fabrication processes. In this work, simple metal- $\mathrm{LiNbO}_{3}$ - metal structures have been developed to fabricate single FBAR elements directly connected to each other on a single chip. A fabrication process based on $\mathrm{LiNbO}_{3} /$ silicon $\mathrm{Au}-\mathrm{Au}$ bonding and $\mathrm{LiNbO}$ lapping/polishing has been developed and is proposed in this paper. Electrical measurements of these FBAR filters are proposed and commented exhibiting filters with $8 \%$ of fractional bandwidth and $3.3 \mathrm{~dB}$ of insertion losses. Electrical measurements show possibilities to obtain $14 \%$ of fractional bandwidth. These devices have been packaged, allowing for power handling, thermal, and ferroelectric tests, corresponding to spatial conditions.
\end{abstract}

\section{Introduction}

Acoustic waves, using surface or bulk propagation, are used in numerous applications in frequency generation, control, or filtering in modern wireless communication systems [13]. With the growing demand for multimedia and mobile applications, new generations of telecommunication satellites require higher performances, higher functionalities, and still stronger cost and size constraints $[4,5]$. In that context, bulk acoustic waves (BAWs) or film bulk acoustic resonator (FBAR) devices can offer many potentialities for smart RF components or systems. For instance, this technology is now used as alternative to surface acoustic waves (SAWs) filters in handset duplexers for UMTS and DCS standards around $2 \mathrm{GHz}$ with aluminium nitride piezoelectric layers [6]. This material is mainly processed for local oscillators or narrowband filtering operations $(<5 \%)[7-12]$.

To achieve large bandwidth filters with fractional bandwidth over $10 \%$, higher coupling coefficient materials are required. These materials should be compatible with batch processes as those used for the micro-electromechanical systems (MEMS). The filter conception shows great interest for different orientation cut of $\mathrm{LiNbO}_{3}$. A specific microfabrication process has been developed to achieve such resonators and filters. These devices are characterized to obtain filters behaviour. Finally, packaging of these devices allows testing power, thermal, and ferroelectric behaviours.

\section{Conception}

BAW filters based on electrical couplings are usually designed with series or shunt resonators. By this way, two main topologies are used: the ladder [13] and the lattice [14] ones. ladder topology (Figure 1) is the easiest method to achieve BAW filter. Such a filter exhibits high selectivity but low outof-band rejection.

As one can see in Figure 1, separation between resonance and antiresonance frequencies has a direct impact on the bandwidth of Ladder filter. Piezoelectric materials with high electromechanical coupling coefficient allow the conception of large band pass filters. Indeed, (1) describes the dependence 

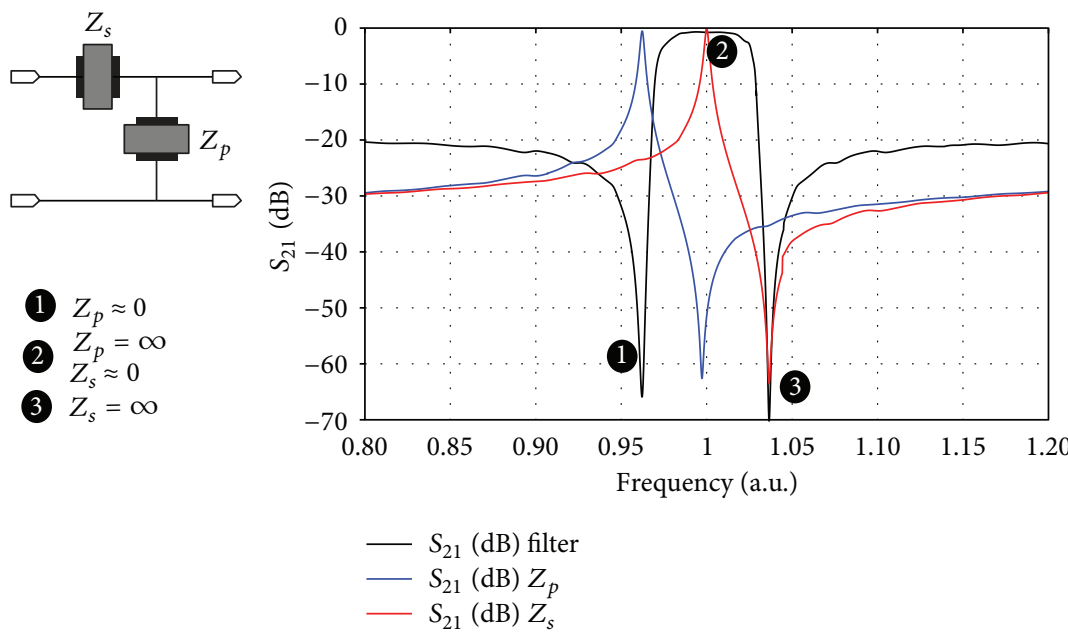

FIGURE 1: 2-pole ladder filter topology.

of $k^{2}$ according to the resonance and antiresonance frequencies. To obtain a filter, the antiresonance frequency of the parallel resonator needs to be at the same frequency as that of the resonance of the series resonator

$$
k^{2}=\frac{\pi^{2}}{4} \frac{f_{p}-f_{s}}{f_{p}} .
$$

Aluminium nitride presents a coupling coefficient around 7\% [9]. But these values of electromechanical coupling coefficient are too low for large band specifications. Two $\mathrm{LiNbO}_{3}$ cut orientations show high coupling coefficient for only one kind of volume wave, as shown in Figure 2. $\mathrm{LiNbO}_{3} \mathrm{YXl} / 36^{\circ}$ has a coupling coefficient for longitudinal mode of $31.7 \%$, and $\mathrm{LiNbO}_{3} \quad \mathrm{YXl} / 163^{\circ}$ has a coupling coefficient for longitudinal mode of $53.3 \%$.

Using these material properties, large band pass filter can be designed. Ladder filter using three resonators based on $\mathrm{LiNbO}_{3} \mathrm{YXl} / 36^{\circ}$ membrane presents a fractional bandwidth of $16 \%$ (Figure 3).

\section{Microfabrication}

Conception of such devices needs to have membrane of $\mathrm{LiNbO}_{3}$ with bottom and top electrodes. Frequency shift between resonators is obtained with a third metallic layer, used as loading layer. To achieve this structure, the fabrication process is based on gold bonding silicon and $\mathrm{LiNbO}_{3}$ wafer and lapping/polishing step of $\mathrm{LiNbO}_{3}$ wafer, as described in papers mentioned in $[15,16]$. This new process needs more technological developments. Technological works were focus on one hand on insertion of different technological steps before, during, and after bonding and grinding technological step, as shown in Figure 4, and on the other hand on industrialization process and stability.

Deep reaction ion etching (DRIE) of silicon is performed to start the fabrication process. On the $\mathrm{LiNbO}_{3}$ wafer, titanium bottom electrodes are patterned. The mass loading layer

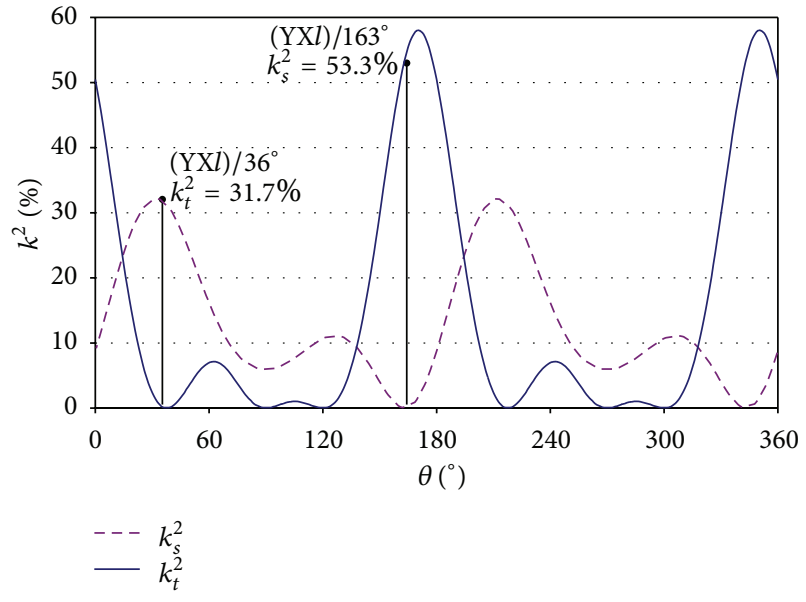

FIGURE 2: The electromechanical coupling coefficient of $\mathrm{LiNbO}_{3}$ for different $(\mathrm{YXl})$ cut orientation and for two volume waves: the longitudinal wave $\left(k_{t}^{2}\right)$ and the shear wave $\left(k_{s}^{2}\right)$.

was patterned on bottom electrode to prevent the membrane from breaking down. Chromium and gold sputtering are deposited on both silicon and $\mathrm{LiNbO}_{3}$ wafers. The Gold and the chromium layers on $\mathrm{LiNbO}_{3}$ wafer are patterned to avoid unwanted electrical connection between the resonators of the filter. The Gold bonding is made with a wafer bonder EVG machine. This bonding is checked by transmitted ultrasonic characterization, as shown Figure 5. In this scan, the red area corresponds to the well-bonding zone and the green areas correspond to the membranes. The lapping and polishing steps are performed to obtain thin membrane around $10 \mu \mathrm{m}$, and the bottom aluminium electrodes are patterned.

Development of this process allows obtaining a membrane on $\mathrm{LiNbO}_{3}$, as shown Figure 6. This technology 


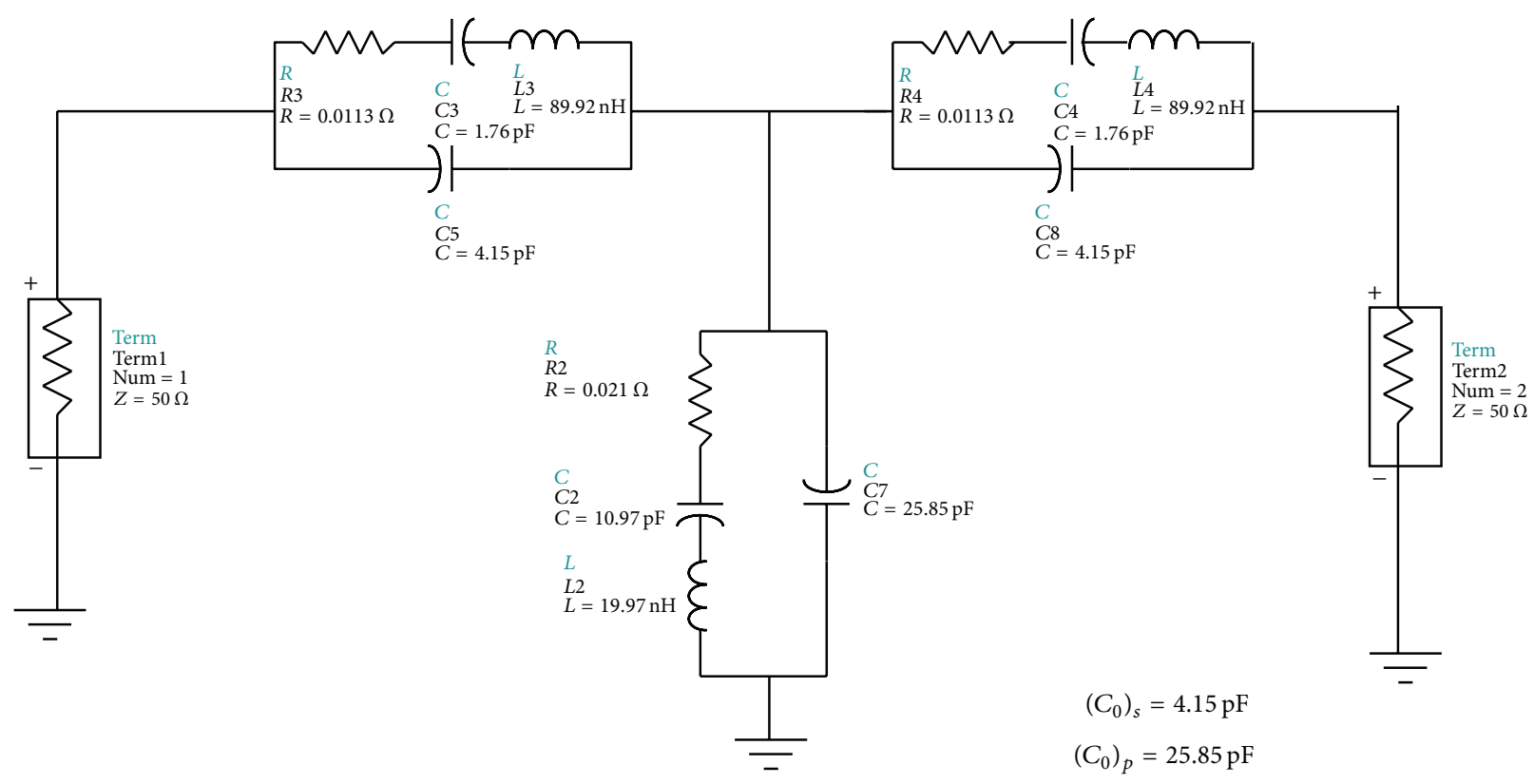

FIGURE 3: 3-pole filter simulation using MBVD model.

presents two major drawbacks: the membrane weakness and the difficulty to tune the final frequency by local etching of the top electrode.

One well-known solution is the SMR (solidly mounted resonator) solution [17]. Bragg mirror can be fabricated using dielectric sputtering layer or stack obtained by the same technology as shown in Figure 7. With Bragg mirror, filter could be easily tuned and could present better mechanical stability. However, Bragg mirror imposes the frequency range of the filter and a new conception is necessary for a new frequency.

\section{Measurements and Discussion}

First electrical measurements of resonators validate the conception. Figure 8 shows electrical responses of two resonators fabricated with different orientation cut of $\mathrm{LiNbO}_{3}$. The first resonator is based on $\mathrm{LiNbO}_{3} \mathrm{YXl} / 163^{\circ}$ membrane. The electromechanical coupling coefficient of the fundamental mode is around $31 \%$, whereas the theoretical one is 37\% [18] (Figure 8(a)). The second resonator is done with $\mathrm{LiNbO}_{3} \mathrm{YXl} / 36^{\circ}$ membrane. The electromechanical coupling coefficient of the fundamental mode is $20 \%$ (Figure $8(\mathrm{~b})$ ). Several electrical characterizations are made after different polishing steps during the fabrication process. The membrane thickness decreases clearly during the different polishing steps.

Based on these developments, filter devices have been manufactured. Figure 9 shows the corresponding electrical behaviour for fundamental resonance and large bandwidth measurements. Although in-band ripples were observed due to electromechanical coupling overestimations, the responses of the devices were found in agreement with the expected

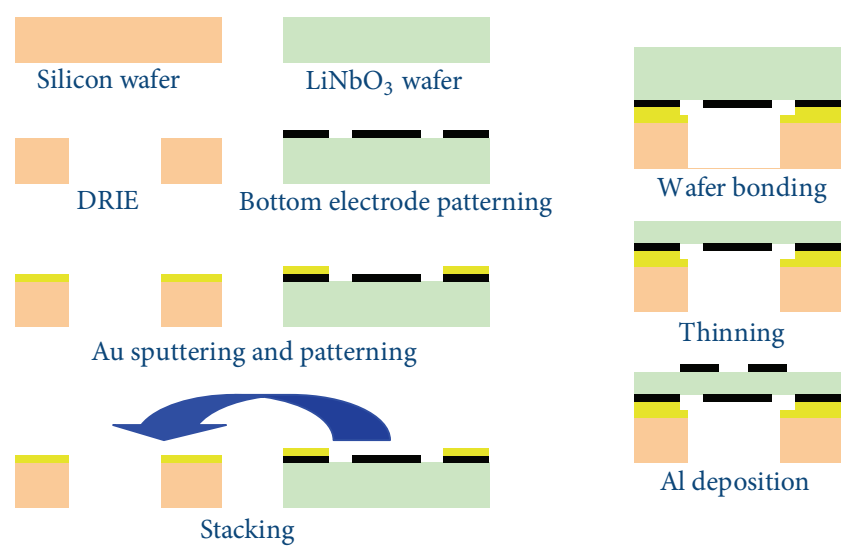

FIGURE 4: Flowchart process for the fabrication of the FBAR based on bonding and lapping technology.

behaviours. For the fundamental mode, insertion losses of $3.3 \mathrm{~dB}$ are obtained with fractional bandwidth around $14 \%$, if we do not take into account the notch due to a wrong thickness ratio between the Pt loading layer and piezoelectric layer. Due to this mismatch of the loading layer, the parallel resonator is not at the good frequency, creating a dip in the pass band of the filter. This measured fractional bandwidth is very similar to the predicted one with our computation method (15.6\%). The thickness of the $\mathrm{LiNbO}_{3}$ layer is around $10 \mu \mathrm{m}$. Better control of the loading layer will enable the improvement of the filter behaviour.

Packaging of these devices allows testing behaviour under different conditions. Firstly, power tests of one resonator and one filter are done at room temperature, $-20^{\circ} \mathrm{C}$, and $+60^{\circ} \mathrm{C}$ for 


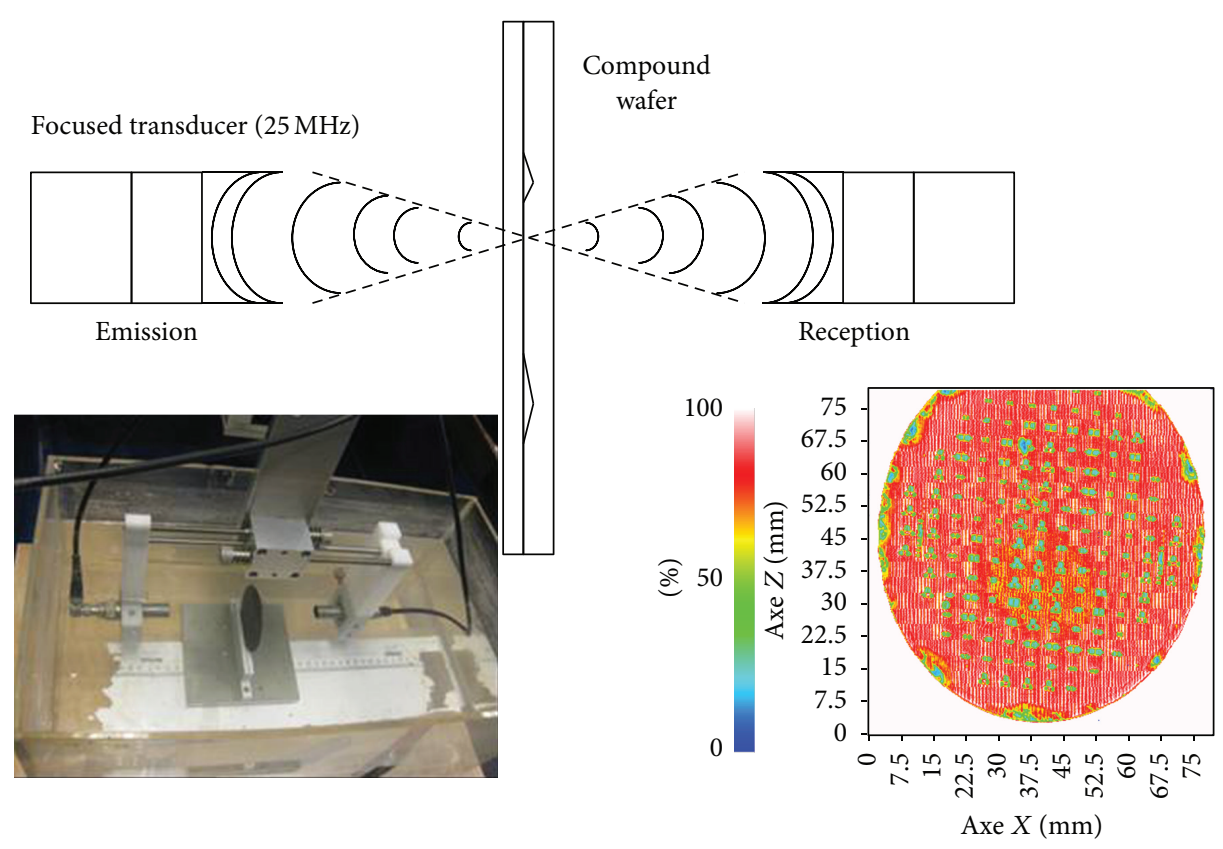

FIGURE 5: Ultrasonic bench for the characterization of silicon and $\mathrm{LiNbO}_{3}$ wafer bonding and scan of the transmission characterization.

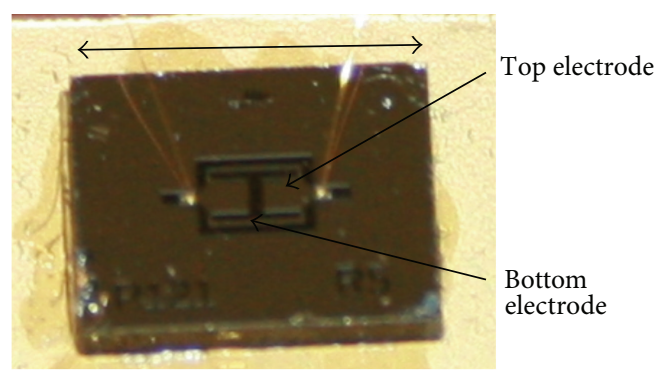

FIGURE 6: Resonator based on $\mathrm{LiNbO}_{3}$ membrane.

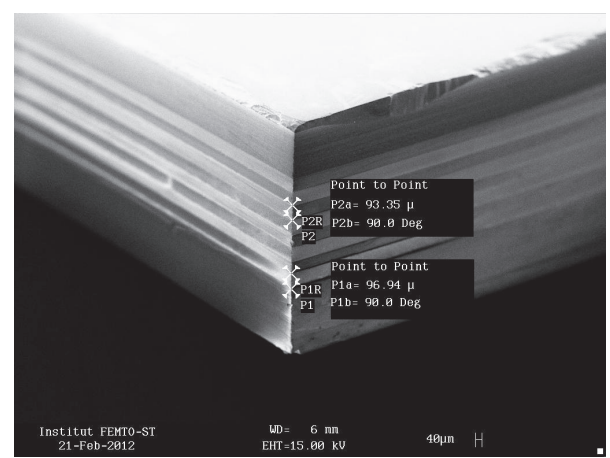

FIGURE 7: Bragg mirror is composed four pairs of quartz and lithium of tantalate.

$-10 \mathrm{dBm}, 0 \mathrm{dBm},+5 \mathrm{dBm},+10 \mathrm{dBm}$, and $+15 \mathrm{dBm}$. Filter and resonator electrical responses present no change for all the tested power. Secondly, thermal shocks are performed on one resonator. One hundred thermal chocks between $-50^{\circ} \mathrm{C}$ and $125^{\circ} \mathrm{C}$ are done. Electrical measurements before and after this test do not reveal the failure of the resonator. The resonator presents exactly the same electrical characteristics before and after the thermal shocks. Although, these tests do not constituted a complete and formal evaluation of reliability, these preliminary results are very promising for the proposed technology.

As shown in Figure 10, relative frequency shift with temperature between $-20^{\circ} \mathrm{C}$ and $+60^{\circ} \mathrm{C}$ is $61 \mathrm{ppm} \cdot \mathrm{K}^{-1}$. To address the radio-frequency applications, compensation of temperature effect will be required. This compensation could be done with voltage control of the frequency and temperature measurement. To check if the ferroelectric effect of $\mathrm{LiNbO}_{3}$ can be used to achieve this function, DC voltage has been added on top electrodes, and frequency variation is observed. The measured relative frequency shift with DC voltage is $6 \mathrm{ppm} \cdot \mathrm{V}^{-1}$. To achieve higher frequency shift due to ferroelectric effect, DC voltage must be applied near $\mathrm{YX} l / 90^{\circ}$ direction and in smaller distance. Top electrodes are separated by around $100 \mu \mathrm{m}$, whereas thickness membrane is around 10 to $30 \mu \mathrm{m}$. So, the temperature compensation needs to be done with DC voltage applied between bottom and top electrodes to obtain more frequency shift with the same DC value. To do that, fabrication process needs to be completed to achieve vias to the bottom electrode.

\section{Conclusion}

Large band filter applications can be addressed with filters based on $\mathrm{LiNbO}_{3}$ membrane. Generic microfabrication of such filters shows possibilities to adapt process for other devices which can address different applications such as energy harvesting. Some test vehicles have been successfully 


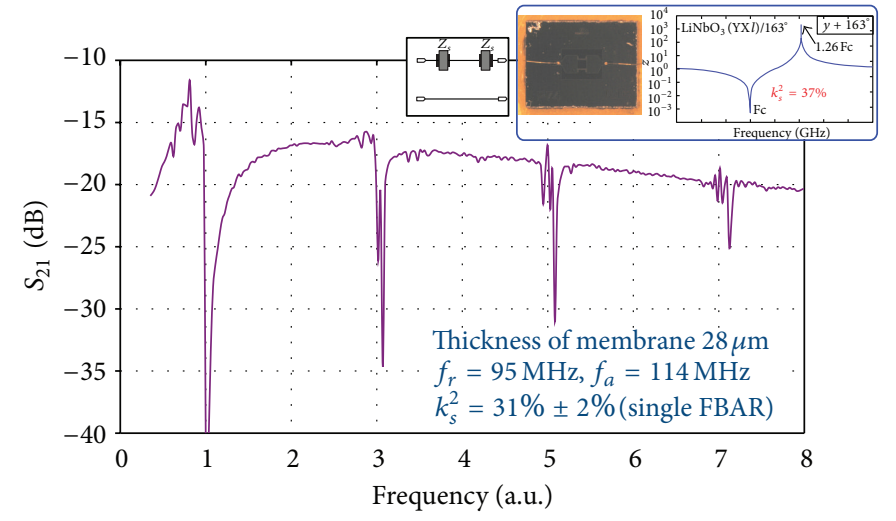

(a)

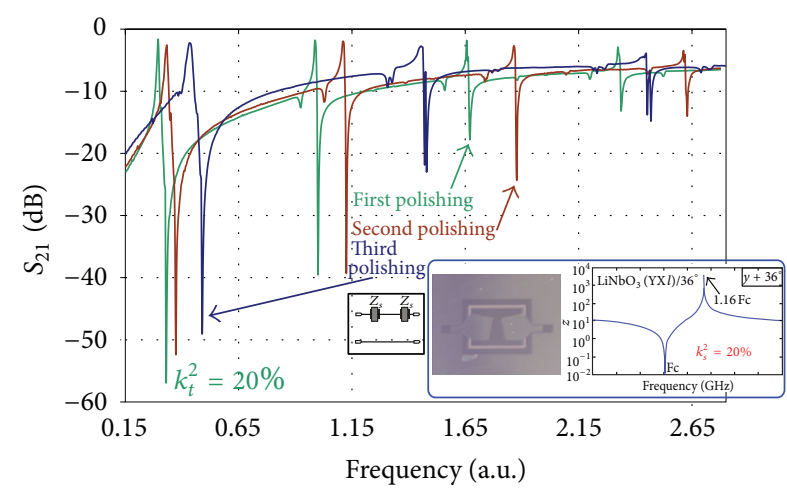

(b)

Figure 8: Electrical measurement of the first resonator based on $\mathrm{LiNbO}_{3} \mathrm{YXl} / 163^{\circ}$ membrane (a) and the second resonator based on $\mathrm{LiNbO}_{3}$ $\mathrm{YX} l / 36^{\circ}$ membrane (b).

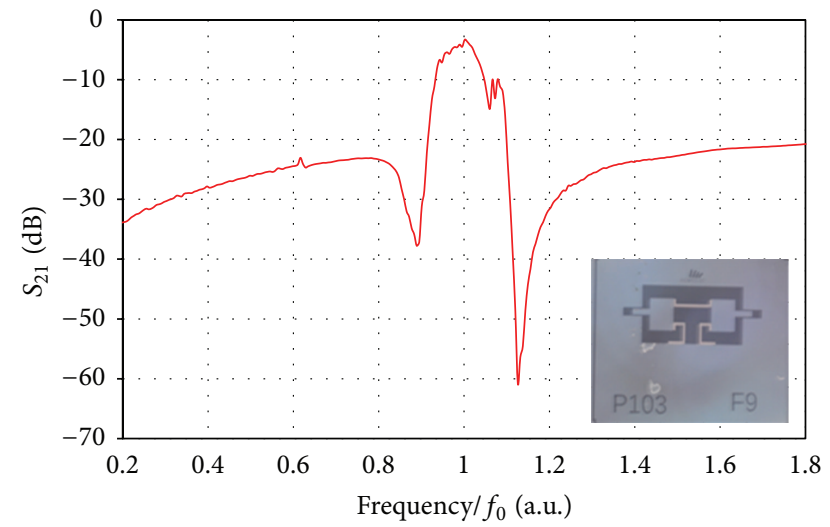

FIGURE 9: Electrical measurements of filters based on $\mathrm{LiNbO}_{3}$ $\mathrm{YXl} / 36^{\circ}$ membrane after several polishing steps.

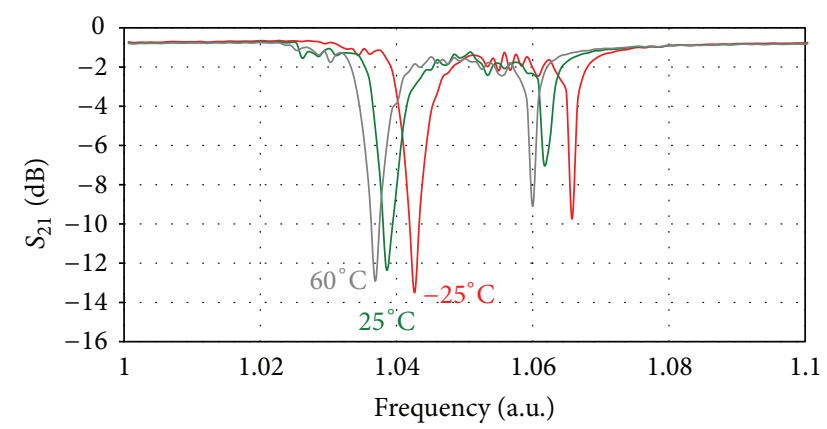

FIGURE 10: Electrical measurements of resonators at three different temperatures.

fabricated. Electrical responses of the filters fabricated confirm potentiality for space applications. Future work on technology will be done to increase frequency, and better control on thickness ratio of piezoelectric layer and mass loading layer will improve fractional bandwidth. However, the filter presents a significant thermal sensibility. This drawback can be easily improved by the use of ferroelectric properties of $\mathrm{LiNbO}_{3}$.

\section{Acknowledgments}

The authors want to thank Lionel Portal for the electrical characterizations. This work was supported by the CNES under Grant no. R\&T R-S08/TC-0001-026 through the FOVETTES Project.

\section{References}

[1] K. M. Lakin, G. R. Kline, and K. T. McCarron, "High Q microwave acoustic resonators and filters," in Proceedings of the IEEE MTT-S International Symposium on Circuits and Systems, pp. 1517-1520, June 1993.

[2] R. Aigner, "SAW and BAW technologies for RF filter applications: a review of the relative strengths and weaknesses," in Proceedings of IEEE Ultrasonics Symposium, Beijing, China, 2008.

[3] A. Flament, A. Frappe, B. Stefanelli et al., "A complete UMTS transmitter using BAW filters and duplexer, a $90 \mathrm{~nm}$ CMOS digital RF signal generator and a $0.25 \mu \mathrm{m}$ BiCMOS power amplifier," International Journal of RF and Microwave ComputerAided Engineering, vol. 21, no. 5, pp. 466-476, 2011.

[4] R. Aigner, J. Kaitila, J. Ellä et al., "Bulk-acoustic-wave filters: performance optimization and volume manufacturing," in Proceedings of the IEEE MTT-S International Microwave Symposium Digest, pp. 2001-2004, Philadelphia, Pa, USA, June 2003.

[5] P. Bar, A. Giry, P. Triolet et al., "Full-duplex receiver and PA integration with BAW devices," in Proceedings of the IEEE Topical Meeting on Silicon Monolithic Integrated Circuits in RF Systems (SiRF '08), pp. 9-12, January 2008.

[6] S. Giraud, S. Bila, M. Chatras, D. Cros, and M. Aubourg, "Bulk acoustic wave filters synthesis and optimization for multi-standard communication terminals," IEEE Transactions on Ultrasonics, Ferroelectrics, and Frequency Control, vol. 57, no. 1, pp. 52-58, 2010. 
[7] A. Reinhardt, G. Parat, E. Defä̈, M. Aïd, and F. Domingue, "Acoustic technologies for advanced RF architectures," in Proceedings of the 8th IEEE International NEWCAS Conference (NEWCAS '10), pp. 161-164, June 2010.

[8] R. Lanz and P. Muralt, "Solidly mounted BAW filters for $8 \mathrm{GHz}$ based on AlN thin films," in Proceedings of the IEEE Ultrasonics Symposium, pp. 178-181, October 2003.

[9] Akyiama, Journal of Advanced Materials, 2009.

[10] X. Zhu, V. Lee, J. Phillips, and A. Mortazawi, "An intrinsically switchable FBAR filter based on barium titanate thin films," IEEE Microwave and Wireless Components Letters, vol. 19, no. 6, pp. 359-361, 2009.

[11] H. Yu, W. Pang, H. Zhang, and E. S. Kim, "Ultra temperaturestable BAW resonators with $\mathrm{SiO} 2$ compensation layer," IEEE Transactions on Ultrasonics Ferroelectrics and Frequency Control, vol. 54, no. 10, pp. 2102-2109, 2007.

[12] K. Y. Hashimoto, "Demands of highly piezoelectric materials for radio frequency acoustic wave devices," Physica Status Solidi A, vol. 208, no. 5, pp. 1084-1092, 2011.

[13] L. Catherinot, S. Giraud, M. Chatras et al., "A general procedure for the desing of BAW filters," International Journal of RF and Microwave Computer-Aided Engineering, vol. 21, no. 5, pp. 458465, 2011.

[14] A. A. Shirakawa, J. B. David, P. Vincent, M. El Hassan, E. Kerhervé, and A. Cathelin, "A mixed ladder-lattice bulk acoustic wave duplexer for W-CDMA handsets," in Proceedings of the 14th IEEE International Conference on Electronics, Circuits and Systems (ICECS '07), pp. 554-557, December 2007.

[15] T. Baron, J. Masson, J.-P. Romand et al., "BAW pressure sensor on $\mathrm{LiNbO}_{3}$ membrane lapping," in Proceedings of the 24th European Frequency and Time Forum (EFTF '10).

[16] T. Baron, E. Lebrasseur, J. P. Romand et al., "Temperature compensated radio-frequency harmonic bulk acoustic resonators pressure sensors," in Proceedings of the IEEE Ultrasonics Symposium (IUS '10), San Diego, Calif, USA, 2010.

[17] M. Gilles and M. Thomas, "New trends in piezoelectric devices for RF application in mobile phones," in Proceedings of the 2nd International Workshop on Piezoelectric MEMS, 2011.

[18] M. Chatras, L. Catherinot, S. Bila et al., "Large band-pass BAW filter for space applications," in Proceedings of the IEEE Frequency Control and the European Frequency and Time Forum (FCS '11), pp. 472-474, 2011. 

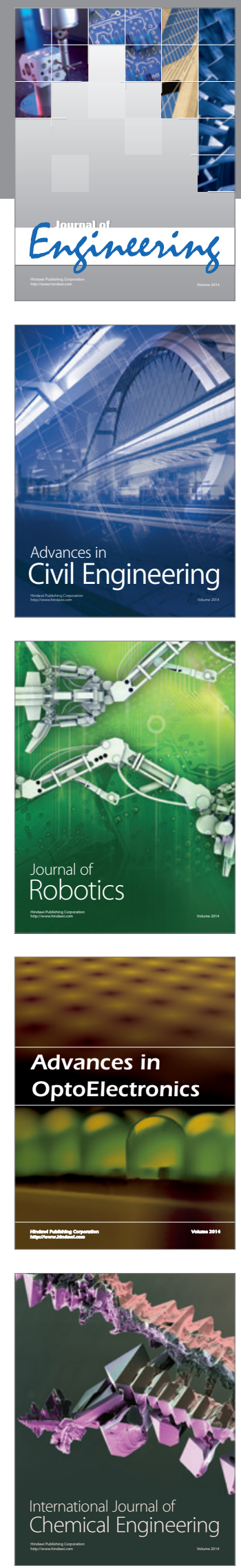

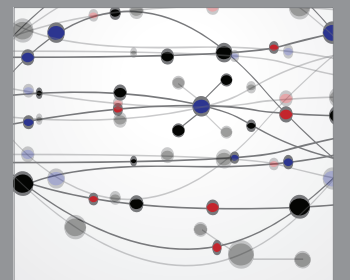

The Scientific World Journal
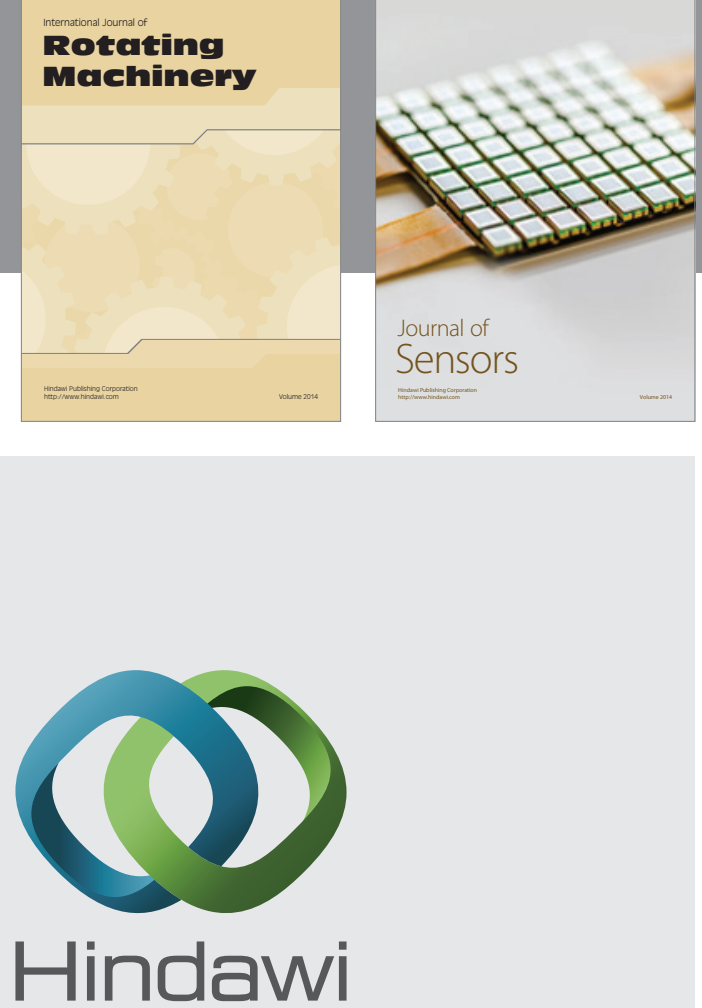

Submit your manuscripts at http://www.hindawi.com
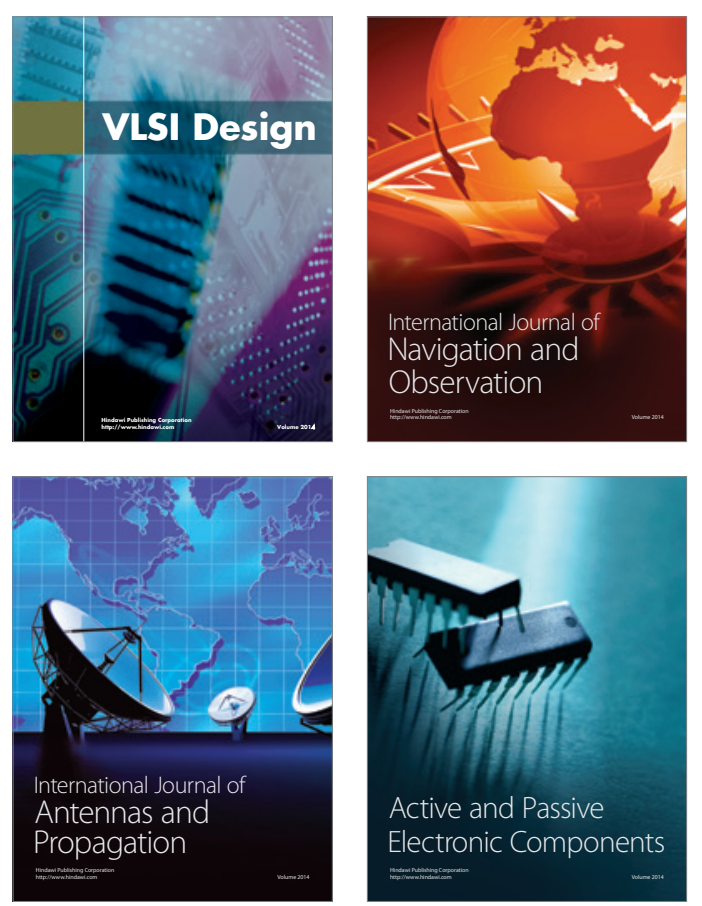
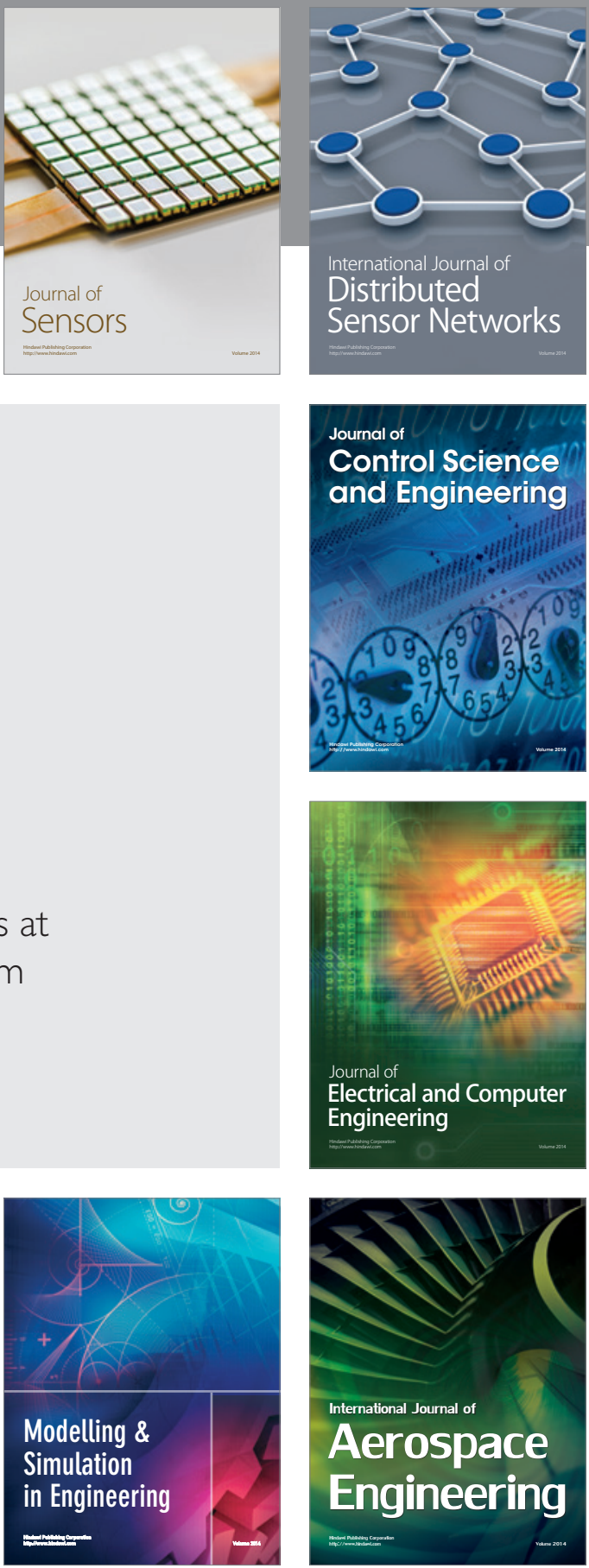

Journal of

Control Science

and Engineering
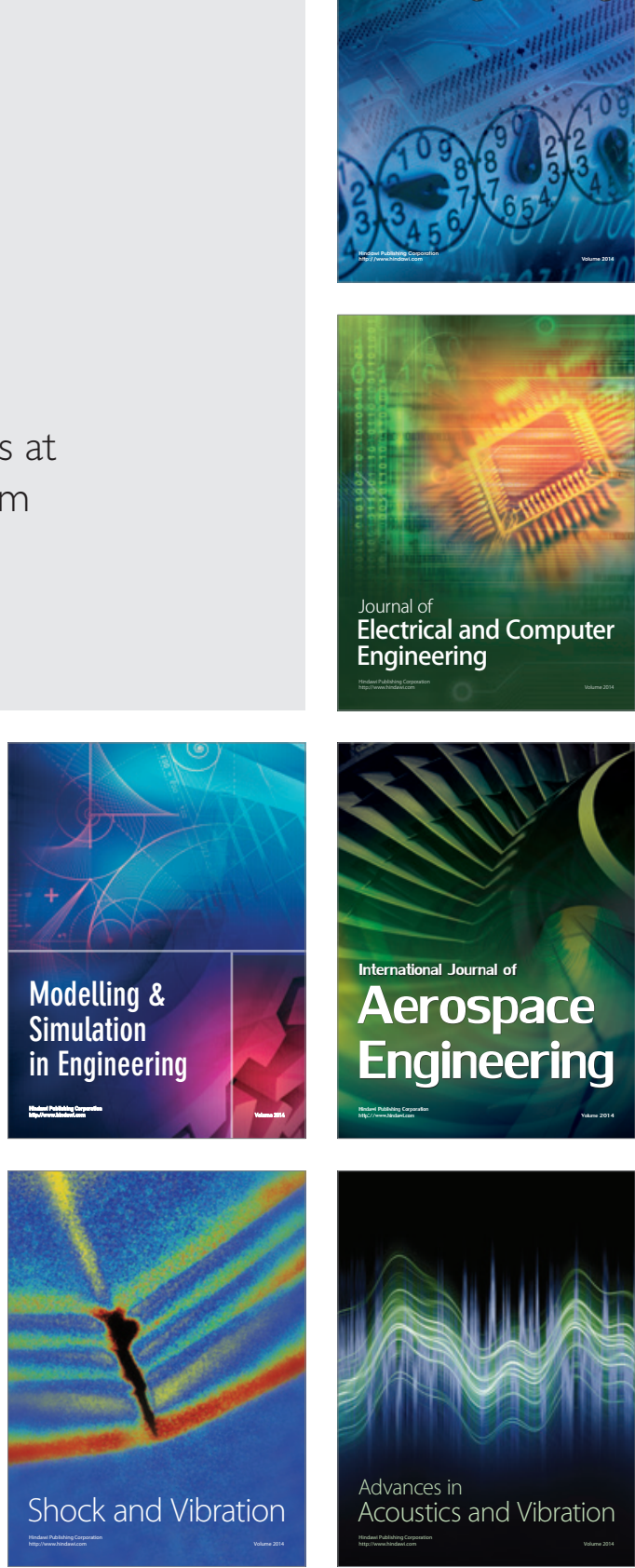